\title{
Nitrogen fertilisation management in precision agriculture: a preliminary application example on maize
}

\author{
Raffaele Casa, Andrea Cavalieri, Benedetto Lo Cascio \\ Department of Crop Production, University of Tuscia, Viterbo, Italy
}

\begin{abstract}
The adoption of precision agriculture techniques for $\mathrm{N}$ management has the potential for improving agronomic, economic and environmental efficiency in the use of such input. The present work was aimed at testing a simplified $\mathrm{N}$ balance method for the prescription of $\mathrm{N}$ fertilisation in uniform management zones defined from information on measured soil properties on grain maize in central Italy. The results of this preliminary experience show that the application of the $\mathrm{N}$ balance prescription map did not bring to significant differences, from a uniform $\mathrm{N}$ fertilisation, in terms of grain yield, economic return above $\mathrm{N}$ cost and nitrate content in the soil profile at the end of the growing season. However, the adoption of the prescribed $\mathrm{N}$ fertilisation strategy for the whole field would have caused a limited saving in the amount of fertiliser employed, quantified at about $10 \mathrm{~kg} \mathrm{~N} \mathrm{ha}^{-1}$.
\end{abstract}

\section{Introduction}

More than 20\% of the European Union (EU) countries ground waters are facing excessive nitrates concentrations, with a continuous

Correspondence: Dr. Raffaele Casa, Department of Crop Production, University of Tuscia, via San Camillo de Lellis, 01100 Viterbo, Italy. Tel: +39.0761.3575554 - Fax: +39.0761.357558. E-mail: rcasa@unitus.it

Key words: nitrogen balance, spatial variability, variable rate application, uniform management zones, nitrogen fertilisation.

Received for publication: 28 September 2010.

Accepted for publication: 21 December 2010.

Acknowledgement: the authors acknowledge the support provided by Maccarese SpA staff, in particular Claudio Destro, Marco Borella and Enrico Gazzola. Fabio Pieruccetti and Francesco Nassetti helped with soil analysis and field work. This work was partially funded by projects PRAL 2003/12 "APreCeL", PRIN 2006 and PRIN 2008.

CC Copyright R. Casa et al., 2011

Licensee PAGEPress, Italy

Italian Journal of Agronomy 2011; 6:e5

doi:10.4081/ija.2011.e5

This article is distributed under the terms of the Creative Commons Attribution Noncommercial License (by-nc 3.0) which permits any noncommercial use, distribution, and reproduction in any medium, provided the original author(s) and source are credited. increasing trend in the most intensive areas of livestock breeding and fertiliser consumption (European Environment Agency, 2005). The agricultural origin of these nitrogen (N) fluxes accounts for $50-80 \%$ of total $\mathrm{N}$ inputs to EU waters (European Commission, 2002). Legislative measures adopted to comply with the Directive 91/676/EEC concerning the "Protection of Waters against Pollution caused by Nitrates from Agricultural Sources", in some cases did not obtain the expected results and are not always accepted (or complied with) by farmers (MacGregor and Warren, 2006; Mouratiadou et al., 2010). Encouraging the diffusion of organic farming might not improve this environmental problem, as the risk of $\mathrm{N}$ leaching remains, given the high amounts of organic fertiliser needed to sustain satisfactory yield levels (Aronsson et al., 2007; Mondelaers et al., 2009).

A promising alternative option relies on the introduction of more efficient $\mathrm{N}$ management methods, exploiting the impressive recent technological advances in the fields of information technology, remote sensing, ecophysiology, geostatistics and geo-spatial data management, leading to the development of what is called precision agriculture. A paradigm shift in the philosophy of agronomic management techniques (and research) is needed to drive the adoption of site-specific farming practices (Sørensen et al., 2010). Considerable advantages could result from precise $\mathrm{N}$ management, as a key factor affecting yield, quality and the environment. Moreover, within-field variability of $\mathrm{N}$ processes is the rule rather than the exception, as a result of small-scale soil spatial variability, topography and management history.

Different approaches have been proposed for the management of $\mathrm{N}$ fertilisation in the context of precision agriculture. They span from "on-the-go" methods, in which the fertiliser dose to be applied is determined instantaneously, by taking into account crop status as detected for example by tractor-mounted sensors (Tremblay et al., 2009), to methods based on the definition of $\mathrm{N}$ prescription maps built on spatial information layers (Long et al., 2000). Two main strategies exist for the definition of $\mathrm{N}$ prescription maps. The first assumes the possibility of continuous regulation of $\mathrm{N}$ spreading, leading to the drawing of prescription maps fully reflecting the spatial variability of crop production factors. A second strategy consists in identifying, within a field, relatively homogeneous areas for which prescribed fertilisation rates are constant (uniform management zones, UMZ) (Koch et al., 2004; Basso et al., 2007; Casa and Castrignanò, 2008).

While the first approach is theoretically more correct, the application of such strategy requires the availability, at the farm, of variable rate application (VRA) equipment, currently rather expensive. The second strategy is therefore, in principle, more compatible with the use of agricultural machinery available in most farms.

Whichever method is used, the task of defining the optimal $\mathrm{N}$ dose to apply spatially is not trivial. Methods based on the use of yield response functions to $\mathrm{N}$, define a technically optimal dose as the one for which the marginal $\mathrm{N}$ productivity becomes zero, or an economically optimal dose as the intersection between the line ratio of unit product to unit fertiliser price and the yield response curve (Jaynes, 2010). However, the form of the $\mathrm{N}$ response curves depends on a wide range of factors other than $\mathrm{N}$, making them extremely variable both in 
space and time, so that their use for precision $\mathrm{N}$ management results unrealistic (Mamo et al., 2003). As an alternative, $\mathrm{N}$ fertiliser requirements can be computed by means of a simplified $\mathrm{N}$ balance (Grignani et al., 2003), which may also take into account spatially variable soil properties and management (Long et al., 2000).

A further advantage of the latter method in the context of precision agriculture is that the $\mathrm{N}$ dose prescribed by the $\mathrm{N}$ balance may be split, allowing the fine-tuning of the fertiliser dressing to be regulated by crop nutritional status monitoring methods, such as those based on tractor mounted sensors (Tremblay et al., 2009) or on remote sensing (Blondlot et al., 2005). The present work was aimed at testing a simplified $\mathrm{N}$ balance method for the prescription of maize $\mathrm{N}$ fertilisation amounts for uniform management zones defined from information on soil properties. This research falls into the general objective of examining agronomic, economic and environmental aspects related to the adoption of $\mathrm{N}$ management strategies in precision agriculture for cereal crops in central Italy.

\section{Materials and Methods}

The experiment took place in the commercial farm Maccarese S.p.A. (Fiumicino, Roma, Italy), in a flat land area of about 37 ha (lat $41^{\circ} 52^{\prime} 38^{\prime \prime N}$, long $12^{\circ} 13$ '51'E, $8.7 \mathrm{~m}$ a.s.l.) in the years $2007-2008$ cropped to grain maize. The field is composed by regularly shaped units of about $40 \mathrm{~m}$ in width and about $500 \mathrm{~m}$ in length, separated by ditches. For the purpose of the present study, 4 adjacent such units were selected for a total area of about $10 \mathrm{ha}$. A systematic soil sampling along a grid of $40 \times 40 \mathrm{~m}$ mesh was carried out in April 2007, collecting samples in the $0-30 \mathrm{~cm}$ soil layer for a total of 97 points, georeferenced by a Trimble Pro XRS GPS with post-processing correction, yielding a positional accuracy of about $1 \mathrm{~m}$. For each point, samples from the vertices of a $2 \mathrm{~m}$ side triangle were bulked. Samples were then air-dried and sieved at $2 \mathrm{~mm}$ before particle size analysis (pipette method) and soil organic matter analysis (Springer and Klee method) were carried out. An additional soil sampling was carried out in September 2008 after maize harvest, in order to quantify residual mineral $\mathrm{N}$ in the soil profile. For this purpose, the sampling was planned to cover systematically the whole experimental area for a total of 92 points. Samples were collected for the $0-80 \mathrm{~cm}$ soil layer by means of a hydraulic soil sampler, they were put into a portable fridge, taken to the lab and rapidly analysed for N-NO3- content by the method of Vendrell and Zupancic (1990).

All soil properties data were interpolated by ordinary kriging using a stable or a Gaussian variogram model in order to produce maps of clay, sand, silt and organic matter (Figure 1). The kriged soil data were then clustered into classes by means of a unsupervised fuzzy cmeans classification implemented through the Management Zone Analyst software (Fridgen et al., 2004), allowing the definition of an optimal number of soil classes on the basis of minima of the fuzziness performance index and the normalized classification entropy. These classes were assumed to correspond to uniform management zones (UMZ).

Yield of grain maize was measured in the 2007 and 2008 seasons by means of a yield mapping precision farming system (PFS) installed on board a New Holland CX860 combine harvester, comprising DGPS, grain flow sensor, grain moisture sensor and PFS data management software. A calibration of the grain flow sensor was carried out in 2007 and 2008 by relating quantities measured on the combine to the corresponding weights recorded at the farm balance for a number of grain loads, obtaining a highly significant linear relationship. The calibration of the grain moisture sensor was carried out by manually collecting samples from the combine and directly measuring moisture content after drying in an oven. However, relationships with grain moisture measured at the combine were not consistent. Thus, in this study, yield mapping results are expressed on a wet weight basis. The grain flow sensor calibration relationships were applied to yield mapping data that had been filtered for the removal of erroneous data. For example, data recorded when the DGPS signal was missing, or when the combine was moving at speeds lower than $2 \mathrm{~km} \mathrm{~h}^{-1}$, or when the effective cutting width of the combine had not been set correctly were deleted. Yield mapping data were subsequently converted to the UTM ED50 coordinate system, consistently to soil data, and interpolated by performing kriging with local variograms (Whelan et al., 2002).

In order to compute $\mathrm{N}$ fertilisation rates for the 2008 season, a simplified $\mathrm{N}$ balance (after Grignani et al., 2003) was calculated for each UMZ as:

$$
F c=Y b-A n-M f-M c-S m+S i-R i+Z v+Z l+Z r
$$

where $F c$ is $\mathrm{N}$ fertilizer need, $Y b$ is the $\mathrm{N}$ uptake by the crop at the expected yield level, $A n$ is $\mathrm{N}$ input from dry and wet depositions, $M f$ is residual $\mathrm{N}$ from previous organic fertilisations, $M c$ is $\mathrm{N}$ rapidly mineralised from crop residues, $S m$ is $\mathrm{N}$ mineralized from soil organic matter, $S i$ is N immobilized from previous crop residues, $R i$ is mineral $\mathrm{N}$ available at the beginning of the season, $Z v, Z r$ and $Z v$ are $\mathrm{N}$ losses respectively from volatilisation, leaching and runoff. The expected yield used for calculating the crop $\mathrm{N}$ uptake was assumed to be the mean for the UMZ recorded in 2007 by yield mapping. Other factors were derived from soil texture, organic matter and total $\mathrm{N}$ data or by using empirical coefficients from Grignani et al. (2003) and CRPV (2006). In particular, bulk density was estimated from soil texture, whereas ${\mathrm{N}-\mathrm{NO}^{-}}^{-}$and $\mathrm{N}-\mathrm{NH}_{4}{ }^{+}$were considered as $1 \%$ of the total $\mathrm{N}$. Rates calculated for each UMZ defined the prescription map for maize grown in 2008. The Pioneer PR32F27 hybrid was sown on the $2^{\text {nd }}$ of April 2008 resulting in a density of 6 plants $\mathrm{m}^{-2}$ after full emergence. A herbicide treatment (Isoxaflutole+Flufenacet, $0.5 \mathrm{~kg} \mathrm{ha}^{-1}$ ) was applied on April $8^{\text {th }}$. Irrigation started on May $9^{\text {th }}$ and a total seasonal volume of $1500 \mathrm{~m}^{3} \mathrm{ha}^{-1}$ was applied with 20 days intervals between each watering. A uniform $\mathrm{N}$ fertilisation of $138 \mathrm{~kg} \mathrm{~N} \mathrm{ha}^{-1}$ was applied on the $30^{\text {th }}$ of April as urea ( $\left.46 \% \mathrm{~N}\right)$ at the V3-V4 stage (Iowa State University, 1993). The comparison between variable and uniform $\mathrm{N}$ fertilisation was carried out by differentiating the second $\mathrm{N}$ dressing (urea), which was applied on May $29^{\text {th }}$. For that purpose, the 4 units of the experimental field were split into two halves each, creating 8 strips of about $20 \mathrm{~m}$ width. Uniform or variable $\mathrm{N}$ rate treatments were assigned randomly to each strip, similarly to a randomized block design with 4 replicates. $\mathrm{N}$ rate in the uniform treatment was $92 \mathrm{~kg} \mathrm{~N}$ $\mathrm{ha}^{-1}$ for the whole strip, while it varied between 69 and $92 \mathrm{~kg} \mathrm{~N} \mathrm{ha}^{-1}$ according to the UMZ in the variable rate treatment. The $\mathrm{N}$ dressing was distributed using a Damax fertiliser spreader that had been previously calibrated at the farm. The prescription map was loaded onto a hand held Trimble Juno GPS which alerted the operator to switch between $\mathrm{N}$ rates in the different UMZs.

In order to calculate the economic consequence of the different $\mathrm{N}$ treatments, the return above $\mathrm{N}$ cost (RANC) (Bachmaier and Gandorfer, 2009) was computed as:

$$
R A N C\left(€ h a^{-1}\right)=Y^{*} P g-N^{*} P N \quad(E q .2)
$$

where $\mathrm{Y}$ is the yield $\left(\mathrm{t} \mathrm{ha} \mathrm{a}^{-1}\right), \mathrm{Pg}$ is the price of grain maize $\left(€ \mathrm{t}^{-1}\right)$, $\mathrm{N}$ is the $\mathrm{N}$ fertiliser rate $\left(\mathrm{tha}^{-1}\right)$ and $\mathrm{PN}$ is the price of a unit $\mathrm{N}\left(€ \mathrm{t}^{-1}\right)$. $Y$ was obtained from 2008 yield mapping while for the other terms the values employed where $\mathrm{Pg}=167 € \mathrm{t}^{-1}$ and $\mathrm{PN}=389 € \mathrm{t}^{-1}$ (average prices for the years 2005-2008). 


\section{Results and Discussion}

The examination of the maps of soil properties obtained by kriging reveals the presence of heterogeneity and spatial variability in terms of soil texture and organic matter throughout the experimental area (Figure 1). In particular, the NW part of the field includes a more light textured area that seems to reflect in part into the lower grain maize yields recorded in 2007 (Figure 2a). It should be noted that this area with higher sand percentage does not correspond to the lower organic matter area, since probably the variability in soil organic matter is more influenced by the heterogeneous application of cattle slurry occasionally carried out in the field.

The continuous variability of soil properties could be well represented by 4 soil classes (Figure 3a), as identified from the c-means clustering technique. This number of classes corresponds to the minima of the fuzziness performance index (FPI) and of the normalized classification entropy (NCE) obtained using measured soil characteristics. FPI is a measure of the degree of separation between fuzzy cpartitions and ranges from 0 to 1 , with values approaching 0 indicating distinct classes with little membership sharing (Fridgen et al., 2004). NCE models the amount of disorganisation of a fuzzy c-partition. Differences among soil classes in terms of clay, sand, silt and organic matter were statistically significant $(\mathrm{P}<0.01)$ according to a one-way ANOVA (Table 1).

The $\mathrm{N}$ balance (Eq. 1) was calculated separately for each of the 4 soil classes, using, as an approximate estimate of yield target, the average grain yield obtained in 2007 (which was a good yielding year) for each area corresponding to a given class. The results of the balance indicated an $\mathrm{N}$ need varying from 201 to $239 \mathrm{~kg} \mathrm{~N} \mathrm{ha}^{-1}$ for the different classes (Table 1).

These values corresponded to a prescription of only two possible rates: 69 or $92 \mathrm{~kg} \mathrm{~N} \mathrm{ha}^{-1}$ for the second $\mathrm{N}$ dressing, once the first uniform application of $138 \mathrm{~kg} \mathrm{~N} \mathrm{ha}^{-1}$ had been taken into account and considering the fertiliser spreader regulation resolution of $\pm 23 \mathrm{~kg} \mathrm{~N}$ ha $^{-1}$ (Table 1).

The prescription map for the second $\mathrm{N}$ dressing (Figure $3 \mathrm{~b}$ ) was adhered to, only in randomly selected strips corresponding to half of each field unit as described in the Methods section, whereas a uniform dose of $98 \mathrm{~kg} \mathrm{~N} \mathrm{ha}^{-1}$ was employed for the other halves (Figure $3 c)$. In this way, an experimental scheme approximating a randomized complete block design (RCBD) was adopted, with 4 replicates (blocks) corresponding each to a field unit and two treatments applied in each strip (plot): uniform (UNI) or variable application (VAR).

It should be noted, though, that in such a set-up, with large blocks and plots and a high number of observations within plots as a result of yield mapping, classical RCBD ANOVA could be made more powerful by incorporating spatial correlation into the analysis (Hong et al., 2005). Some authors have proposed appropriate linear mixed model methodologies and procedures for incorporating spatially variable errors and covariates in the data analysis (Hong et al., 2005; Milliken et al., 2005). In our case, however, we only took into account the fact that the proportions of management zones in each given strip were different, by standardizing them to their proportion across the entire field as done for example by Koch et al. (2004).

Grain maize yields in 2008 were generally lower than in 2007, but showed somehow consistent spatial patterns (Figure 2b). The spatial pattern of the computed RANC (Figure 2c) completely reflected the

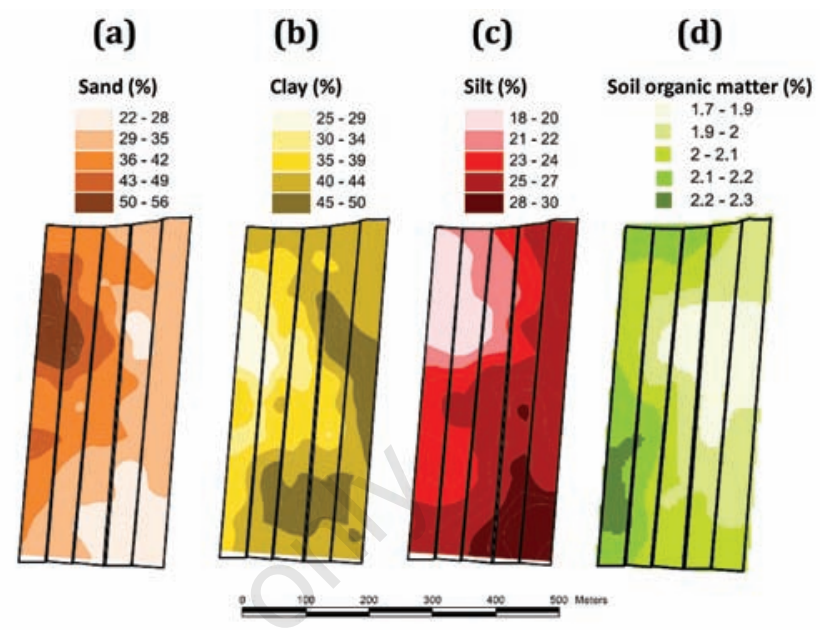

Figure 1. Kriged maps of (a) sand (\% w/w), (b) silt (\% w/w), (c) clay $(\% \mathrm{w} / \mathrm{w})$ and (d) soil organic matter $(\% \mathrm{w} / \mathrm{w})$ for the section of the field under study (field B064) at the Maccarese S.p.A. farm (Fiumicino, Roma). Lines delineate regularly shaped field units delimited by ditches.

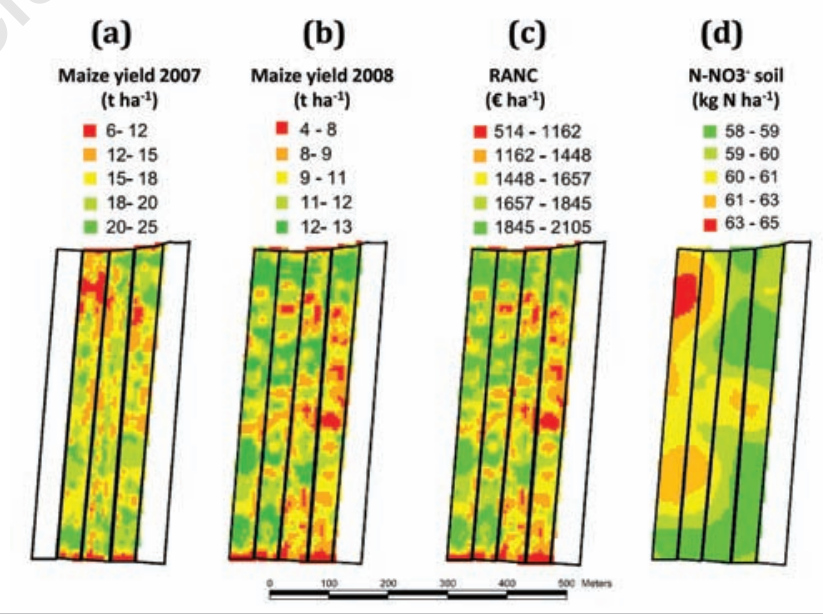

Figure 2. Kriged maps of (a) maize grain yield (wet) in 2007; (b) maize grain yield (wet) in 2008; (c) return above nitrogen cost (RANC) (Eq. 2) in 2008 and (d) $\mathrm{N}_{-} \mathrm{NO}_{3}{ }^{-}$in the $0-80 \mathrm{~cm}$ soil layer measured in September 2008 after maize harvest.

Table 1. Soil properties of the 4 soil classes and resulting $\mathrm{N}$ rate prescription from the simplified $\mathrm{N}$ balance (Eq. 1). Small letters denote values significantly different $(\mathbf{P}<0.01)$ for Tukey's Multiple Comparison test.

\begin{tabular}{|c|c|c|c|c|c|c|c|}
\hline Soil class & $\begin{array}{l}\text { Sand } \\
(\%)\end{array}$ & $\begin{array}{l}\text { oil pro } \\
\text { Silt } \\
(\%)\end{array}$ & $\begin{array}{l}\text { Clay } \\
(\%)\end{array}$ & $\begin{array}{l}\text { SOM } \\
(\%)\end{array}$ & $\begin{array}{c}\mathrm{N} \text { need } \\
\left(\mathrm{kg} \mathrm{N} \mathrm{ha-}^{-1}\right)\end{array}$ & $\begin{array}{l}\mathrm{N} \text { prescription } \\
2^{\text {nd }} \text { dressing } \\
\left(\mathrm{kg} \mathrm{N} \mathrm{ha}^{-1}\right)\end{array}$ & $\begin{array}{c}\text { Prescriber } \mathrm{N} \text { rate } \\
\left(\mathrm{kg} \mathrm{N} \mathrm{ha}^{-1}\right)\end{array}$ \\
\hline A & $36.4^{\mathrm{b}}$ & $22.4^{\mathrm{c}}$ & $41.1^{b}$ & $2.0^{c}$ & 201 & 63 & 69 \\
\hline B & $45.4^{\mathrm{a}}$ & $22.4^{\mathrm{c}}$ & $32.5^{\mathrm{d}}$ & $2.1^{\mathrm{b}}$ & 215 & 77 & 69 \\
\hline $\mathrm{C}$ & $30.2^{\mathrm{d}}$ & $26.8^{\mathrm{a}}$ & $42.7^{\mathrm{a}}$ & $2.0^{c}$ & 239 & 101 & 92 \\
\hline $\mathrm{D}$ & $35.4^{c}$ & $24.0^{\mathrm{b}}$ & $40.7^{c}$ & $2.2^{\mathrm{d}}$ & 237 & 99 & 92 \\
\hline
\end{tabular}


yield map. Overall, the comparison between UNI and VAR N application did not reveal significant differences in terms of yield or RANC averaged over the treatment strips (Figure 4). Nevertheless it can be noted that the adoption of VAR did allow some small saving in terms of $\mathrm{N}$ fertilizer. If the VAR fertilization had been adopted all over the field, it would have led to the application of $150 \mathrm{~kg} \mathrm{ha}^{-1}$ of urea in 3.72 ha and $200 \mathrm{~kg} \mathrm{ha}^{-1}$ of urea in the remaining $5.2 \mathrm{ha}$, bringing about a total saving of $186 \mathrm{~kg}$ of urea, corresponding to $8.11 € \mathrm{ha}^{-1}$, assuming a price of urea of $0.39 € \mathrm{~kg}^{-1}$.

A preliminary assessment of the relative environmental impact of the different fertilisation strategies, can be done by examining the $\mathrm{N}$ $\mathrm{NO}_{3}{ }^{-}$remaining in the soil profile after the maize harvest, which an efficient $\mathrm{N}$ management should tend to minimize in order to reduce leaching risks. Soil nitrate content measured in the $0.80 \mathrm{~cm}$ layer in September 2008 revealed that the spatial variability in $\mathrm{N}_{-} \mathrm{NO}_{3}{ }^{-}$ (Figure 2d) was mainly related to differences in soil texture, with a rather limited range of values, comprised between 57 and $65 \mathrm{~kg} \mathrm{~N}$ $\mathrm{NO}_{3}{ }^{-} \mathrm{ha}^{-1}$. As a result of the spatial variability, the differences between VAR and UNI $\mathrm{N}$ fertilisation were not significant, though VAR strips had always smaller values as compared to UNI strips (Figure 5).

\section{Conclusions}

The results obtained in this preliminary experience on variable $\mathrm{N}$ fertilisation management on grain maize, show that the application of a $\mathrm{N}$ prescription map based on a simplified $\mathrm{N}$ balance for different uniform management zones did not bring to significant differences in terms of grain yield, economic return above $\mathrm{N}$ cost and nitrate content in the soil profile at the end of the growing season, from a uniform $\mathrm{N}$ fertilisation as usually carried out by the farm. The adoption of a variable $\mathrm{N}$ fertilisation strategy for the whole field would have caused, however, a limited saving in the amount of fertiliser employed. These results are not surprising considering that the $\mathrm{N}$ amounts spread in the different management zones (UMZs) differed by only $\pm 23 \mathrm{~kg} \mathrm{~N} \mathrm{ha}^{-1}$. It is possible that larger differences might have been observed if also the first $\mathrm{N}$ dressing had been differentiated among UMZs.

A more reliable definition of UMZs and of the target yield for each zone, than the one carried out in the present work, has been illustrated by several workers. It is possible to employ multi-year yield mapping data as well as simulations using crop models in order to define stable high and low yield potential areas (Basso et al., 2007). Multivariate approaches can also be used for this purpose (Casa and Castrignanò, 2008).

In addition, information on soil properties needs to be obtained in a much more efficient and economic way as compared to the direct soil sampling carried out in our case, for realistic operative precision farming applications. This is an active area of research, exploring, among other things, the possibilities offered by indirect geoelectric techniques (Morari et al., 2009) or by hyperspectral remote sensing for mapping soil texture and organic matter (Casa et al., 2010).

Overall there are good possibilities that the adoption of variable $\mathrm{N}$ application rates according to precision farming concepts could have positive economic results. Lambert and Lowemberg-DeBoer (2000) reviewed 108 studies of which $63 \%$ reported economic benefits for variable rate application (VRA). Similarly, in a review by Griffin et al. (2004), $68 \%$ of the 210 works examined reported an economic advantage of VRA over uniform $\mathrm{N}$ fertilisation. Environmental benefits of $\mathrm{N}$ VRA have been also largely reported (Hong et al., 2006). Nevertheless these aspects are site specific and need to be assessed in the different situation by an appropriate agronomic research targeted to the

peculiarities of precision agriculture field trials, e.g. employing statistical methods which are able to consider the spatial correlation of errors in the ANOVA (Hong et al., 2005; Milliken et al., 2009). More in general, precision agriculture presents to the agronomists the challenge of making good use of the large amount of spatial information available, for example from yield mapping systems and remote sensing, in order to improve the economic and environmental efficiency in the management of resources and inputs in crop production.

(a)

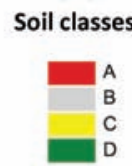

(c) $\mathrm{N}$ applied ( $k$ N ha-1) $\begin{array}{r}69 \\ \hline+92\end{array}$ 92

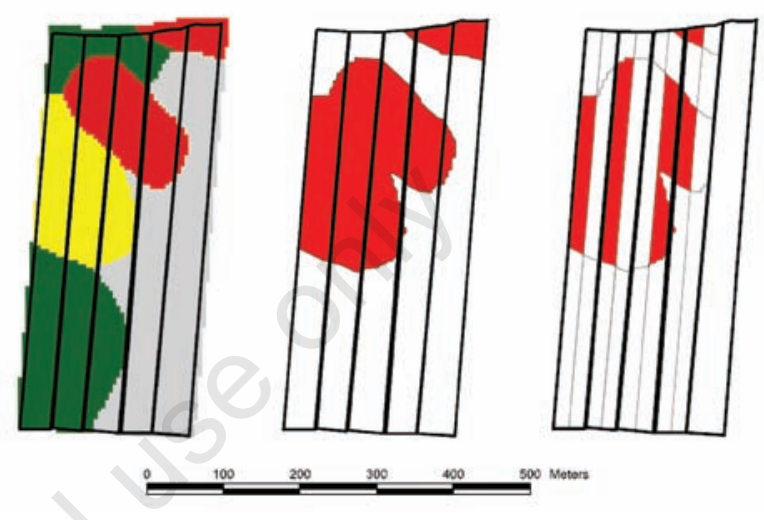

Figure 3. Maps of (a) soil classes as identified by the c-means clustering procedure, (b) corresponding $2^{\text {nd }}$ dressing $N$ prescription map (from Table 1) and (c) $\mathrm{N}$ rate effectively applied.
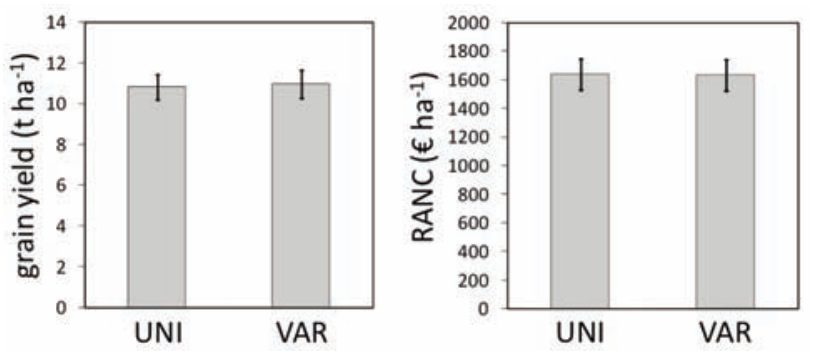

Figure 4. Spatial average results of the comparison between uniform (UNI) and variable (VAR) $\mathrm{N}$ application in terms of (a) maize grain yields (wet) in 2008 and (b) return above nitrogen cost (RANC) (Eq. 2) in 2008.

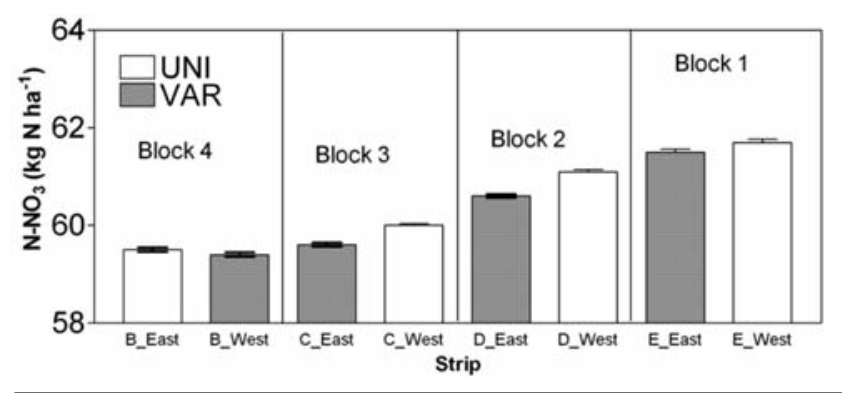

Figure 5. Spatial average results of the comparison between uniform (UNI) and variable (VAR) $\mathrm{N}$ application in terms of $\mathrm{N}-\mathrm{NO}_{3}{ }^{-}$ in the $0-80 \mathrm{~cm}$ soil layer measured after maize harvest, for each treatment strip corresponding to half field unit (i.e. block). 


\section{References}

Aronsson H., Torstensson G., Bergström L., 2007. Leaching and crop uptake of $\mathrm{N}, \mathrm{P}$ and $\mathrm{K}$ from organic and conventional cropping systems on a clay soil. Soil Use Manage. 23:71-81.

Bachmaier M., Gandorfer M., 2009. A conceptual framework for judging the precision agriculture hypothesis with regard to site-specific nitrogen application. Precis. Agric.10:95-110.

Basso B., Bertocco M., Sartori L., Martin E.C., 2007. Analyzing the effects of climate variability on spatial pattern of yield in a maizewheat-soybean rotation. Eur. J. Agron. 26:82-91.

Blondlot A., Gate P., Poilvé H., 2005. Providing operational nitrogen recommendations to farmers using satellite imagery. In: J.V. Stafford (ed.) Precision Agriculture '05. Wageningen University Publ.,Wageningen, The Netherlands, pp 345-351.

Casa R., Castrignanò A., 2008. Analysis of spatial relationships between soil and crop variables in a durum wheat field using a multivariate geostatistical approach. Eur. J. Agron. 28:331-342.

Casa R., Pascucci S., Palombo A., Pignatti S., 2010. Soil texture and organic matter estimation of an agricultural field from hyperspectral remote sensing. Proc. 4th Global Workshop on Digital Soil Mapping, Roma, Italy.

CRPV, Centro Ricerche Produzioni Vegetali, 2006. Disciplinare di produzione integrata, norme generali. Assessorato Agricoltura, Ambiente e Sviluppo Sostenibile, Emilia-Romagna Region, Italy.

European Commission, 2002. The Implementation of Council Directive 91/676/EEC concerning the Protection of Waters against Pollution caused by Nitrates from Agricultural Sources. Available from: http://ec.europa.eu/environment/water/water-nitrates/ report.html.

European Environment Agency, 2005. Source apportionment of nitrogen and phosphorus inputs into the aquatic environment. EEA Report No 7/2005, Copenhagen, Denmark.

Fridgen J.J., Kitchen N.R., Sudduth K.A., Drummond S.T., Wiebold W.J., Fraisse C.W., 2004. Management Zone Analyst (MZA): Software for Subfield Management Zone Delineation. Agron. J. 96:100-108.

Griffin T.W., Lowemberg-DeBoer J., Lambert D.M., Peone J., Payne T., Daberkow S.G., 2004. Adoption, profitability and making better use of precision farming data. Staff paper \#04-06. Purdue University, Dept. of Agricultural Economics, West Lafayette, IN, USA.

Grignani C., Bassanino M., Sacco D., Zavattaro L., 2003. Il bilancio degli elementi nutritivi per la redazione del piano di concimazione. Riv. Agron. 37:155-172.

Hong N., White J.G., Gumpertz M.L., Weisz R., 2005. Spatial analysis of precision agriculture treatments in randomized complete blocks: Guidelines for covariance model selection. Agron. J. 97:1082-1096.

Hong N., White J.G., Weisz R., Crozier C.R., Gumpertz M.L., Cassel D.K., 2006. Remote sensing-informed variable-rate nitrogen management of wheat and corn: Agronomic and groundwater out- comes. Agron. J. 98:327-338.

Iowa State University Extension Service, 1993. How a corn plant develops. Special Report No. 48. Cooperative Extension Service, Ames, Iowa, USA. Available from: http://www.extension.iastate. edu/hancock/info/corn.htm.

Jaynes D.B., 2010. Confidence bands for measured economically optimal nitrogen rates. Precis. Agric. (In press).

Koch B., Khosla R., Frasier W.M., Westfal, D.G., Inman D., 2004. Economic feasibility of variable-rate nitrogen application utilizing site-specific management zones. Agron. J. 96:1572-1580.

Lambert D., Lowenberg-DeBoer J., 2000. Precision agriculture profitability review. Site-specific Management Centre Newsletter, Purdue University, West Lafayette, IN, USA.

Long D.S., Engel R.E., Carlson G.R., 2000. Method for Precision Nitrogen Management in Spring Wheat: II. Implementation. Precis. Agric. 2:25-38.

MacGregor C.J., Warren C.R. 2006. Adopting sustainable farm management practices within a Nitrate Vulnerable Zone in Scotland: The view from the farm. Agr. Ecosyst. Environ. 113:108-119.

Mamo M., Malzer G.L., Mulla D.J., Huggins D.R., Strock J., 2003. Spatial and temporal variation in economically optimum nitrogen rate for corn. Agron. J. 95:958-964.

Milliken G., Willers J., McCarter K., Jenkins J., 2009. Designing experiments to evaluate the effectiveness of precision agricultural practices on research fields: part 1 concepts for their formulation. Operational Research 10:329-348.

Mondelaers K., Aertsens J., van Huylenbroeck G., 2009. A meta-analysis of the differences in environmental impacts between organic and conventional farming. Brit. Food J. 111:1098-1119.

Morari F., Castrignanò A., Pagliarin C., 2009. Application of multivariate geostatistics in delineating management zones within a gravelly vineyard using geo-electrical sensors. Comput. Electron. Agr. 68:97-107.

Mouratiadou I., Russell G., Topp C., Louhichi K., Moran D., 2010. Modelling common agricultural policy-Water Framework Directive interactions and cost-effectiveness of measures to reduce nitrogen pollution. Water Sci. Technol. 61:2689-2697.

Sørensen C.G., Fountas S., Nash E., Pesonen L., Bochtis D., Pedersen S.M., Basso B., Blackmore, S.B., 2010. Conceptual model of a future farm management information system. Comput. Electron. Agr. 72:37-47.

Tremblay N., Wang Z., Ma B.-L., Bélec C., Vigneault P., 2009. A comparison of crop data measured by two commercial sensors for variable-rate nitrogen application. Precis. Agric. 10:145-161.

Vendrell P.F., Zupancic J., 1990. Determination of soil nitrate by transnitration of salicylic acid. Commun. Soil Sci. Plan. 21:10751713.

Whelan B.M., McBratney A.B., Minasny B., 2002. Vesper 1.5 - spatial prediction software for precision agriculture. In P.C. Robert, R.H. Rust and W.E. Larson (eds.) Precision Agriculture, Proc. 6th Int. Conf. on Precision Agriculture, ASA/CSSA/SSSA, Madison, WI, USA. 14 p. 